www.jmscr.igmpublication.org

Impact Factor (SJIF): 6.379

Index Copernicus Value: 71.58

ISSN (e)-2347-176x ISSN (p) 2455-0450

crossref DOI: https://dx.doi.org/10.18535/jmscr/v6i2.202

Journal Of Medical Science And Clinical Research

IGM Publication

An Official Publication of IGM Publication

\title{
Platelet Indices and Special Cytochemical Stains (Intensity) Concomitant Effect-Now A Ancillary Technique and Survival Index for Leukemia Patients
}

\author{
Authors \\ Dr Pankaj Shinde ${ }^{1}$, Dr Sachin Sharma* \\ ${ }^{1}$ Assist. Prof. Email: drpankajshinde@gmail.com \\ *Corresponding Author \\ Dr Sachin Sharma \\ Email: sachinchanderi@gmail.com, 9893166383
}

\begin{abstract}
Aims \& Objective: Our study aims to evaluate the survival index of leukemia patients on the basic of cytochemical staining intensity and platelet count for hematological neoplasm. Concomtant effect of both ancillary technique are simple and cheaper method to confirm the diagnosis and prognosis with survival indexing.

Material \& Methods: Fifty eight patients with suspected clinical and hematological leukemia visiting the central pathology laboratory of medical college were studied .The study used morphology, cytochemical staining of myeloperoxidase (MPO), Sudan black (SBB), periodic acid Schiff (PAS) stain and leukocyte alkaline phosphates staining of blood smear to confirm the diagnosis of leukemia A complete blood counting including $H B \%, P C V$, Red cell indices, platelet count, total white cell count and PDW was done by Automated blood cell counter.

Conclusion: In our study, cytochemistry helped in diagnosis of $62.5 \%$ of AML, $84.2 \%$ of ALL, $14.3 \%$ of $C M L$, none in CLL in addition to morphology in suspected cases of leukemia. Those leukemia have cytochemical positive high intensity with low to variable platelets counts have poor prognosis due to poor survival index..

Keyword: leukemia, cytochemical staining intensity, PDW.
\end{abstract}

\section{Material \& Methods}

Study area and design- The present study was conducted at the Department of Pathology Medical College M.P. The study was designed as a observational hospital based study over a period of time from 2009.

Ethical consideration- Blood was collected in a sterile EDTA containing tube and processed following our established hospital based laboratory protocol then generate the report of each patient. Take informed consent was obtained from all study participant for use of your blood sample for medical research after doing physician investigating and generate the report. Start proper management as a guide line.

Patient's selection criteria-The study target those patients who's present with any complain 
due to high Total WBC count. We include both OPD and IPD patients with all age groups, male and female both gender for study. Sample size is 58 patients.

Complete blood count (cbc) and peripheral smear for cytochemical analysis. a complete blood counting including $\mathrm{hb} \%, \mathrm{pcv}$, red cell indices ,platelet count, total white cell count and pdw was done by automated blood cell counter.

\section{Materials}

The present study was carried out on 58 patients in central pathology laboratory of a tertiary care hospital over a span of two year.

In all the suspected leukemic cases detailed history was taken and clinical findings were noted. Diagnosis and typing of leukemia was done on basis of clinical, haematological, morphological findings and cytochemistry of abnormal cells.

(i) Estimation of haemoglobin, packed cell volume, white blood cell count and platelet count were done by Automated three part cell counter (Medonic CA-530).

(ii) Peripheral blood smear were stained with leishman's stain and differential count done by counting 200 cells.Blood smear were stained for various cytochemical stains i.e. Myeloperoxidase(MPO), Sudan black B (SBB), Periodic acid Schiff (PAS)and Alkaline phosphatase.

(iii) All the above stains were prepared by standard methods.

The peripheral smear in all cases were first studied by leishman stain to make a provisional diagnosis of the type of leukemia.
This was followed by staining with myeloperoxidase stain Sudan black B, periodic acid Schiff (PAS) stain and leukocyte alkaline phosphates was done in cases of chronic myeloid leukemias. The final diagnosis was then made and the two results were compared.

\section{Hematological examination-}

Hematological examination including $\mathrm{HB} \%, \mathrm{PCV}$, Red cell indices, platelet count and total white cell count with differential count should be done on peripheral smears stained with field $\mathrm{A}$ and $\mathrm{B}$ stains.

\section{Observation \& Discussion}

A total of 58 cases of leukemia were studied. The aim was to study whether cytochemical stains aided typing of leukemia. Of 58 cases studied $43(74 \%)$ cases were of acute leukemias and remaining $15(26 \%)$ were of chronic leukemias.

Table No. 1 Showing different type of leukemias

\begin{tabular}{|l|c|c|}
\hline Type of leukemia & No. of cases & Percentages \\
\hline AML & 24 & 41.4 \\
\hline ALL & 19 & 32.7 \\
\hline CML & 14 & 24.1 \\
\hline CLL & 01 & 1.8 \\
\hline TOTAL CASES & 58 & 100.0 \\
\hline
\end{tabular}

Table No. 2 Showing different type of immature cells of leukemia.

\begin{tabular}{|l|c|c|}
\hline Type of Immature cells & No. of cases & Percentages \\
\hline Myloblast & 38 & 65.5 \\
\hline Lymphoblast & 20 & 34.5 \\
\hline TOTAL CASES & 58 & 100.0 \\
\hline
\end{tabular}

This table shows commonest leukemia was AML (41.4\%) followed by in decreasing order: ALL $(32.7 \%)>\operatorname{CML}(24.1 \%)>\operatorname{CLL}(1.8 \%)$.

Table No. 3 Showing age distribution of cases

\begin{tabular}{|l|c|c|c|c|c|c|c|c|}
\hline \multirow{2}{*}{$\begin{array}{l}\text { Age } \\
\text { years }\end{array}$} & \multicolumn{2}{|c|}{ AML } & \multicolumn{2}{c|}{ ALL } & \multicolumn{2}{c|}{ CML } & \multicolumn{2}{c|}{ CLL } \\
\cline { 2 - 9 } & No. & \% & No. & \% & No. & \% & No. & \% \\
\hline 16 & 04 & 16.6 & 13 & 68.4 & - & - & - & - \\
\hline $31-40$ & 05 & 20.8 & 04 & 21.0 & 02 & 14.3 & - & - \\
\hline Above 45 & 10 & 41.6 & 01 & 5.2 & 11 & 78.5 & - & - \\
\hline
\end{tabular}

Acute myeloblastic leukemia is more common in adult patient $20(83.4 \%){ }^{2}$ Acute lymphoblastic leukemia is more common in childhood $13(68.4 \%)^{3,4}$ Chronic myeloid leukemia and chronic lymphocytic leukemia are more common in middle aged with 12 cases $(78.5 \%)$ and 01 case $(100 \%)$ respectively. 
Table 4 Showing number of cases with positive staining

\begin{tabular}{|l|c|c|c|c|c|c|c|c|}
\hline & \multicolumn{2}{|c|}{ AML } & \multicolumn{2}{c|}{ ALL } & \multicolumn{2}{c|}{ CML } & \multicolumn{2}{c|}{ CLL } \\
\hline & $+\mathrm{VE}$ & $\%$ & $+\mathrm{VE}$ & $\%$ & $+\mathrm{VE}$ & $\%$ & $+\mathrm{VE}$ & $\%$ \\
\hline MPO & 24 & 100 & 02 & 10 & 14 & 100 & 0 & 0 \\
\hline SBB & 24 & 100 & 01 & 05 & 14 & 100 & 0 & 0 \\
\hline PAS & 0 & 0 & 19 & 100 & 1 & 07 & 1 & 100 \\
\hline
\end{tabular}

Acute myeloblastic leukemia is more common in adult patient 20 (83.4\%) 14 Acute lymphoblastic leukemia is more common in childhood 13 (68.4\%) 11,12 Chronic myeloid leukemia and chronic lymphocytic leukemia are more common in middle aged with 12 cases(78.5\%) and 01 case $(100 \%)$ respectively.

\section{Data Analysis}

This study comprised 58 individuals (male and female and all age group). Blood samples were collected by venipuncture in tubes containing EDTA anticoagulant (ethylene diamine. The platelet indices were analyzed in whole blood using a blood cell counter The factorial ANOVA mode lwith Tukey's test was used for statistical analysis and an alpha error of $5 \%$ (p-value < 0.05 ) was considered acceptable. In relation to gender, significant differences were observed for leukemia. In regards to age, there were significant differences in the values for the type of leukemia comparing the under 10-year-old age group to the other age groups except for the all age group. Data analysis in following hematological parameters with the difference under the Extended Mantel-Haenszel test for trend of chi -Squares test. Chi-sq. test X2 Value $=0.873[\mathrm{DF}=1] 2$ sided $\mathrm{P}=0.350$ For trend in a given direction: $\mathrm{P}$ $=0.175$

\section{Conclusion}

Leukemia is found in all parts of the world and constitutes an important cause of death at all ages. Considerable research work is going on to solve the mystery of leukemia.

In the present study 58 cases of leukemia were studied. Out of this 43 , (74\%) were cases of acute leukemia and the remaining 15(26\%) were chronic leukemias.

Out of 43, 24 cases (41.4\%) were of AML and 19 cases $(32.7 \%)$ were of ALL showing a slight higher incidence of AML as compared to ALL.

Our study confirms the time old statement that ALL is mainly a disease of childhood while AML is mainly a disease of adults.

Patients of acute leukemia mainly suffered from moderate to severe anemia, considerable leucocytosis and thrombocytopenia in the present study. Subclassification of AML and ALL was done and studied according to FAB classification.

Acute myeloblastic leukemia were mainly of M2 variety $(37.5 \%)$, M4 comprise $29.2 \%$ cases, M1 comprise $25 \%$ of cases and M3 comprise $8.3 \%$ of cases.

In the present study, there were no cases belonging to M0, M5, M6 and M7 subtype. Sultan et al (1981)89 recorded most common type of AML were M2 (32\%) and M1 (21\%), M4 and M5 in their study were almost equal $(16 \%$ and $12 \%$ respectively) while M6 was uncommon accounting only for $3 \%$ cases. Whittaker et al (1979)97 found highest incidence of M2 (63.5\%) followed by M4 (17.5\%) and less common M1, M3, M5 and M6.Among ALL, L1 subtype was more common than L2 subtype.

No case of L3 were recorded inthe study. Among 15 cases of chronic leukemia, one was of chronic lymphocytic leukemia and rest 14 were of CML. All cases of chronic myeloid leukemia were adults i.e. more than fifteen years of age and most of the cases $(92.8 \%)$ fall in $15-45$ years of age group.

The present study undertook four special staining procedures- myeloperoxidase, Sudan black, periodic acid Schiff and alkaline phosphatase. The diagnostic cytochemical stain was block like PAS84 positivity of lymphoblast and negative staining with myeloperoxidase 12 and Sudan Black B and MPO43 and SBB3 positivity and 
PAS negativity of myeloblast. A positive myeloperoxidase staining is indicated by the presence of coarse brown granules in the cytoplasm. Sudan Black B positive stain was observed as black granules in the cytoplasm of leucocytes. Out of 14 cases of CML, 12cases were diagnosed on leishman stain. Two cases (14\%) was confusing. Thus keeping in mind differential diagnosis as a leukaemoid reaction, alkaline phosphatase content was determined. It was found to be reduced in this particular case.

Thus we concluded that the case was of CML and not of leukemoid reaction. CLL was diagnosed as such with leishman stain and did not need cytochemistry for diagnosis Cytochemistry was absolutely essential in 15 cases $(62.5 \%)$ of acute myelobastic leukemia, 9cases (37.5\%) were diagnosed on leishman stain.

The diagnostic cytochemical stain were Myeloperoxidase and Sudan Black B positivity in more than $3 \%$ of myeloblast9.

Out of 19 cases of acute lymphoblastic leukemia 3 cases $(15.8 \%)$ were diagnosed on Leishman stain, 16 cases $(84.2 \%)$ require cytochemical stain for diagnosis. In this study, it was observed that the promyelocytes and myelocyte were most strongly staining cells in the granulocyte series with positive granules packing the cytoplasm. Similar results were observed by Yam LT et al (1994)10.It was observed that MPO stain helps in distinguishing between myeloblast and lymphoblast and thus helped us in typing of Leukemia.

In our study, we observed low LAP activity in cases of chronic myeloid leukemia. The finding was similar to that observed in other studies.

\section{References}

1. Rajnikant Ahirwar1, Rajendra Kumar Nigam2, Reeni Malik3, Suhas Kothari 4, Rubal Jain5 CYTOCHEMICAL ANALYSIS IN LEUKEMIA. Journal of evolution of medical and dental sciences August 2015 vol 4 issue 64 page 1114611156 .
2. Antonio M. Almeida, Fernando Ramos Acute myeloid leukemia in the older adults Leuk Res Rep. 2016; 6: 1-7

3. Neglia, if', and Robison, LL." Epidemiology of the childhood acute leukemias." Pediatr. Clin. North Am., 1988; 35: 675-692.

4. Ribera JM, Oriol A." Acute lymphoblastic leukemia in adolescents and young adults." Hematol Oncol Clin North Am. 2009; 23(5): 1033-42.

5. Alvi, ILA. Saleem, M., Ahmad, P., etal. "A study of hundred cases of acute leukemia in Northern Pakistan with reference to French-American-British (FAB) cooperative group classification". Fl,' 1990; 87-92.

6. Chaudhry, M.T., Tavyab, M. and Farooqui, I.A. Acute non- lymphoblastic leukemia in adults. J. Pak, Med. Aaaoc., 1993; 43: 259- 61.

7. Sultan C, Dereghaucourt J, Ko YW et al. Distribution of 250 cases of acute myeloid leukemia (AML) according to FAB classification and response to therapy. $\mathrm{Br}$. J. Haematol, 47:545-551,1981.

8. Whitaker JA et al: Leukemia classification a study of the accuracy of diagnosis in 456 patients British J Hematol 41;177189,1979

9. Schmalzl F, Braunsteiner $\mathrm{H}$ : The application of cytochemical methods to the study of acute leukemia. A review Acta Haematol 45:209,1971.

10. Bennett JM et al: Proposals for the classification of the acute leukemias. Br. J. Haematol 33:451:1976.

11. Hayhoe FGJ and Quaglino D and Doll R (1964): The cytology and cytochemistry of acute leukemias. A study of 140 cases. Medical Reserach Council special report series No. 304, London Her Majesty's stationery office 1964.

12. A D Glick, K.Panikar, Flexner J: Acute leukemias of adult - ultrastructural, 
cytochemicals and histologic observation in 100 cases. Am J. Clin Pathology 73:459-470, 1980.

13. Cortes JE, Kantarjian HM. Acute lymphoblastic leukemia: a comprehensive review with emphasis on biology and therapy. Cancer.1995;76(12):2393-2417

14. Yam LT: Cytochemistry and immunochemistry in hematologic diagnoses. Hematol Oncol Clin North Am 8:665-681, 1994.

15. Ray Mr; Cytochemical \& Biochemical study of alkaline phosphatase. Medical Journal Armed forces India Vol. 32 No. 1, 43,19 